\title{
Influence of Wettability and Mechanical Properties on Tribological Performance of DLC Coatings under Water Lubrication
}

\author{
Chaoqun Zhang, Masahiro Fujii \\ Graduate School of Natural Science and Technology, Okayama University, Okayama, Japan \\ Email: gen423025@s.okayama-u.ac.jp
}

Received 22 April 2015; accepted 2 June 2015; published 8 June 2015

Copyright (C) 2015 by authors and Scientific Research Publishing Inc.

This work is licensed under the Creative Commons Attribution International License (CC BY). http://creativecommons.org/licenses/by/4.0/

(c) (i) Open Access

\section{Abstract}

DLC coatings are currently used in a wide variety of industrial fields because of their outstanding properties such as high hardness, high wear resistance, low friction and so on under oil lubrication as well as no lubrication. In order to evaluate the tribological performance of DLC coatings under water lubrication, eight types of DLC coatings were evaluated by water-lubricated sliding tests at sliding velocities of $0.02 \mathrm{~m} / \mathrm{s}$ and $0.1 \mathrm{~m} / \mathrm{s}$. The different DLC coating types comprised both hydrogenated and hydrogen-free DLC films that were deposited using different techniques: amorphous hydrogenated DLC (a-C:H), that doped with tungsten (a-C:H:W), that doped with silicon (a-C:H:Si) and hydrogen-free DLC (ta-C). DLC coatings showed low friction coefficient and excellent wear resistance. Friction coefficient and wear rate decreased with increasing sliding velocity. The effect of surface wettability and mechanical properties on tribological characteristics was investigated. Friction coefficient decreased as the contact angle increased. Hydrogen-free DLC coating with the highest hardness showed the highest friction and a larger wear rate. Furthermore, DLC coatings deposited with interlayer showed longer lifetimes.

\section{Keywords}

DLC, Friction, Wettability, Hardness, Water Lubrication

\section{Introduction}

Water lubrication system is a candidate of a substitution for conventional oil lubrication systems to resolve the environment pollution of oil lubricant. The conventional use of oil lubrication systems in equipment has some disadvantages of environmental damage from leakage, risk of fire, and environmental load. While water lubrica- 
tion systems could eliminate these disadvantages, they have tribological problems such as high friction and wear due to the low lubricating propertiy [1]-[3]. Furthermore, the corrosion induced by water would restrict the application of metallic materials in the water lubrication systems. In addition, in the food industry, it is important to avoid contamination of foodstuffs with lubricating oil. From the viewpoint of environmental protection, it is desirable to use water without additives, such as corrosion inhibitors, lubricating additives, and so on. An alternative approach is to take advantage of the metallic materials modified with depositing hard coatings with good lubricity in water environment [4].

DLC coatings are well known to possess self-lubricating property even without lubrication [5] [6]. DLC coatings have high hardness, low friction performance and high wear resistance in unlubricating conditions [7]-[9]. Recently, it has been shown that DLC coatings also have good lubricity with water lubrication [10]-[14]. DLC coatings can be a good candidate for a tribological coating for water lubrication. DLC coatings cover a wide range of films with different compositions and structures, and the basic properties of DLC films with respect to their $\mathrm{sp}^{2}, \mathrm{sp}^{3}$ and $\mathrm{H}$ contents [5]. Such a wide range of film structures and compositions and the diversity of methods available for the production of DLC films are not possible with other types of hard coatings [8] [15]. The aim of this paper was to understand the tribological behavior of DLC coatings under water lubrication, and to evaluate the suitable DLC coatings under water lubrication. Amorphous hydrogenated DLC (a-C:H), tungsten contained DLC (a-C:H:W), silicon contained DLC (a-C:H:Si), and the hydrogen free DLC (ta-C) were deposited by several deposition methods. The sliding tests were carried out under mean pressure $p_{0}=10 \mathrm{MPa}$ and two kinds of sliding velocities with a ring-on-disk apparatus under water lubrication. It is known that the mechanical properties of the DLC coatings are an important factor of the tribological properties [16] [17]. However, the mechanical properties of the DLC coatings varied even deposited by the same process. In this study, the hardness and Young's modulus of DLC coatings were measured. The wettability of DLC coatings was also investigated. The relations with the tribological behavior of DLC coatings were evaluated.

\section{Experimental}

\subsection{Specimen}

Figure 1 showed the shapes and dimensions of test disk and ring. The test disk and ring were made of martensitic stainless steel (JIS SUS440C). The diameter and the thickness of disk were $40 \mathrm{~mm}$ and $10 \mathrm{~mm}$, respectively. The inside diameter and the outside diameter of ring were $20 \mathrm{~mm}$ and $25.5 \mathrm{~mm}$, respectively. The height of the ring was $15 \mathrm{~mm}$. The specimens were finished by grinding after quenching and tempering, and the surface roughness was approximately $0.01 \mu \mathrm{m}$ Ra. The Vickers hardness was around HV670.

\subsection{DLC Coatings}

DLC coatings were deposited on the ring and disk surfaces by physical vapor deposition (PVD), plasma chemical vapor deposition (CVD), or cathode arc ion plating. The coating specifications were summarized in Table 1. DLC-1 and DLC-2 were hydrogenated amorphous carbon coatings (a-C:H) deposited by PVD with a CrN interlayer in order to improve adhesion. DLC-2 was doped with some tungsten (a-C:H:W). DLC-3 was a hydrogenated amorphous carbon coating (a-C:H) deposited by PVD. DLC-4 was a hydrogenated amorphous carbon coating (a-C:H) deposited by multiple methods of PVD and CVD, and doped with some silicon (a-C:H:Si). DLC-5, DLC-6 and DLC-7 were a hydrogenated amorphous carbon coating (a-C:H) deposited by plasma CVD. DLC-8 was a hydrogen-free tetrahedral amorphous coatings (ta-C) deposited by cathode arc ion plating.

Figure 2 showed the Scanning Electron Microscope (SEM) observations of the cross sections of DLC coatings. As shown in Figure 2, DLC coatings had different film thickness. DLC-1, DLC-3, DLC-4 and DLC-8 had

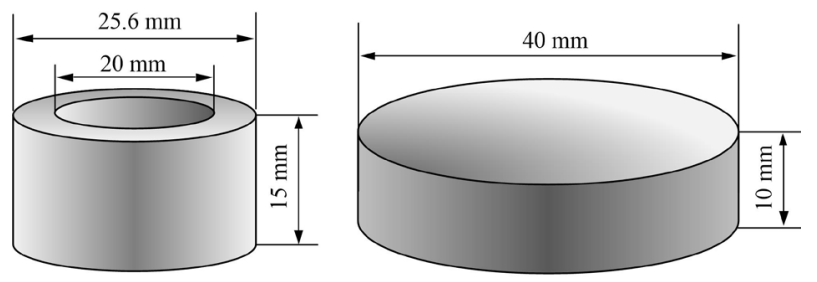

Figure 1. Test ring and disk. 


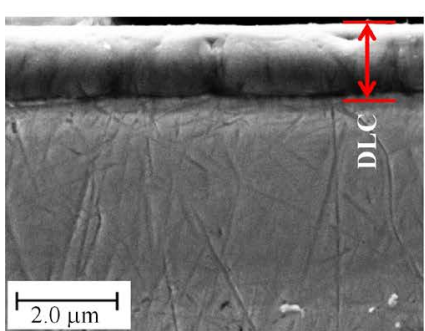

(a)

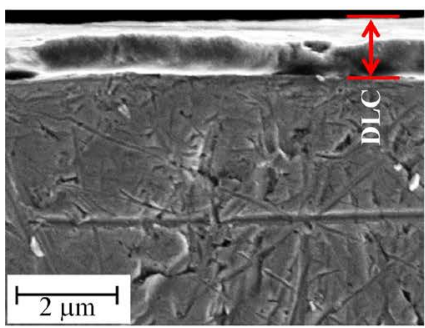

(d)

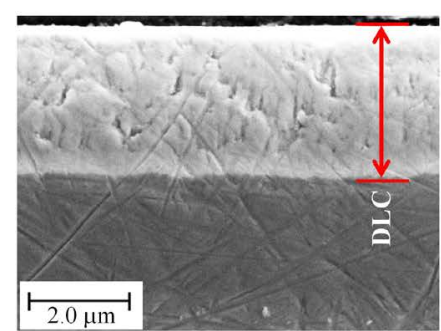

(b)

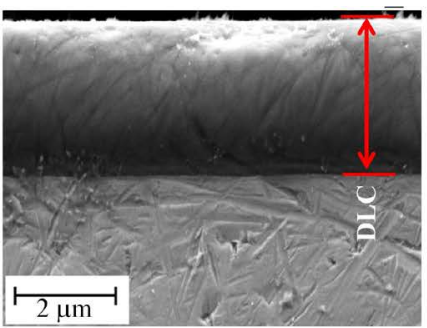

(e)

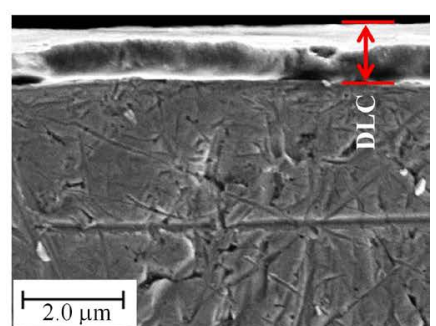

(c)

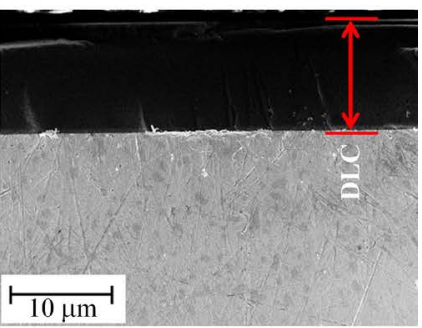

(f)

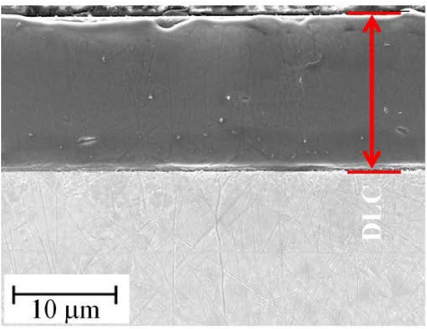

(g)

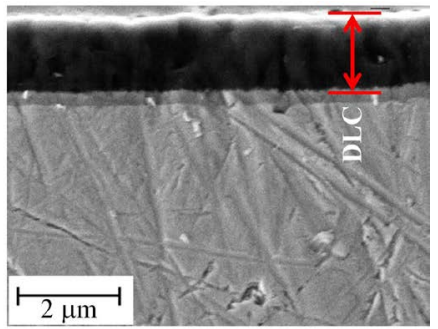

(h)

Figure 2. SEM observations of cross sections. (a) DLC-1; (b) DLC-2; (c) DLC-3; (d) DLC-4; (e) DLC-5; (f) DLC-6; (g) DLC-7; (h) DLC-8.

Table 1. Specifications of DLC coatings.

\begin{tabular}{rccccc}
\hline Coating & Process & Structure & Interlayer & Thickness $(\mu \mathrm{m})$ & Roughness Ra $(\mu \mathrm{m})$ \\
\hline DLC-1 & PVD & $\mathrm{a}-\mathrm{C}: \mathrm{H}$ & $\mathrm{CrN}$ & 1.2 & 0.017 \\
DLC-2 & PVD & a-C:H:W & CrN & 2.9 & 0.013 \\
DLC-3 & PVD & a-C:H & - & 1.3 & 0.015 \\
DLC-4 & Plasma CVD + PVD & a-C:H:Si & - & 0.9 & 0.016 \\
DLC-5 & Plasma CVD & a-C:H & - & 3.0 & 0.016 \\
DLC-6 & Plasma CVD & a-C:H & - & 9.9 & 0.014 \\
DLC-7 & Plasma CVD & a-C:H & - & 15.0 & 0.015 \\
DLC-8 & Cathode arcion plating & ta-C & - & 1.2 & 0.015 \\
\hline
\end{tabular}

a comparatively thin film thickness of approximately $1 \mu \mathrm{m}$. DLC-2 and DLC-5 had a comparatively thick film thickness of approximately $3 \mu \mathrm{m}$. DLC-6 and DLC-7 had the thicker film thick of $9.9 \mu \mathrm{m}$ and $15 \mu \mathrm{m}$. The surface roughness of the DLC coatings was equivalent to that of substrates. Therefore, the influence of surface roughness on friction and wear could be negligible.

\subsection{Sliding Test}

Friction and wear properties were evaluated using a ring-on-disk type tribometer. The tests were performed at 
room temperature under water lubrication. In order to keep the water temperature constant the water was circulated at a rate of $200 \mathrm{~mL} / \mathrm{min}$. The ring specimen was installed on rotating shaft and the ring was installed on the loading shaft. The surface pressure was $10 \mathrm{MPa}$, the sliding velocities Vs were $0.02 \mathrm{~m} / \mathrm{s}$ and $0.1 \mathrm{~m} / \mathrm{s}$. Total sliding distance in each experiment was set to $10,000 \mathrm{~m}$ except when DLC coating was delaminated. In order to observe the variation of surface characteristic during sliding test, the test was intermediated at an interval of 2500 $\mathrm{m}$ and measured the surface characteristics. The friction coefficient was calculated with the measured friction force and normal force. The wear masses of both disk and ring were measured using the electronic balance with a minimum measurement of $10^{-4} \mathrm{~g}$. Before and after each sliding test, the ring and the disk were ultrasonic cleaned in an acetone for one hour, then dried in the vacuum chamber for one hour to remove contaminants.

\section{Experimental Results and Discussion}

\subsection{Friction}

DLC coatings have low friction performance and high wear resistance in unlubricated and in dry atmospheres [9] [12], which has been widely reported by several authors. DLC coatings will be shown good tribological properties under water lubrication, because of DLC coatings are known to possess self-lubricating property even without lubricant. Figure 3 showed the relation between steady-state friction coefficient $\mu$ and sliding distance $\mathrm{L}$ of eight kinds of DLC coatings with sliding velocities of $0.02 \mathrm{~m} / \mathrm{s}$ and $0.1 \mathrm{~m} / \mathrm{s}$ under water lubrication. The friction coefficients at the same sliding distance were averaged and are displayed in the figure along with an error bar that shows the maximum and minimum friction coefficient during the measurements. In order to compared with DLC coatings, the sliding test was carried out for the substrate material SUS440C and the result of friction coefficient, generally about $\mu=0.55$. As shown in Figure 3, DLC coatings showed a large range of friction coefficient values $(0.05-0.5)$ and a large range of fluctuation for the eight kinds of DLC coatings, although DLC coatings showed lower friction coefficients than that of the substrate material SUS440C. DLC-1, DLC-2 and DLC-3 whose coatings were deposited with PVD showed obvious difference of friction properties. In the slower velocity of $0.02 \mathrm{~m} / \mathrm{s}$, DLC-1 showed the highest average friction coefficient $(0.10-0.40)$ and with a large fluctuation among the three DLC coatings, especially in the section L $=2500-5000 \mathrm{~m}$ and L $=5000-7500 \mathrm{~m}$. DLC-2 showed a steady friction coefficient $(0.10-0.20)$. DLC-3 showed the lowest friction coefficient and with a smaller fluctuation among the three DLC coatings, but DLC-3 showed the shortest sliding life because in L = 2500 - $5000 \mathrm{~m}$ the damage was occurred. In contrast, in the higher velocity of $0.1 \mathrm{~m} / \mathrm{s}$, DLC-1, DLC-2 and DLC3 showed similar properties of friction behaviors. DLC-1 and DLC-2 showed higher and un-steady friction coefficients in the section $\mathrm{L}=0$ - $2500 \mathrm{~m}$. Thus, they slightly decreased and became steady when the sliding distance exceed L = $2500 \mathrm{~m}$. DLC-3 showed the shortest sliding life when L = 2500 - $3000 \mathrm{~m}$ the damage was occurred. DLC-4 deposited by multiple methods of PVD and CVD doped with some silicon showed a low friction coefficient $(0.10-0.25)$ in sliding velocity of $0.02 \mathrm{~m} / \mathrm{s}$, and showed a lower and a steady friction coefficient $(0.05-$ 0.15 ) in sliding velocity of $0.1 \mathrm{~m} / \mathrm{s}$. DLC-5, DLC-6 and DLC-7 whose coatings were deposited with CVD showed lower and steady friction coefficients $(0.05-0.2)$ in both of sliding velocity of $0.02 \mathrm{~m} / \mathrm{s}$ and $0.1 \mathrm{~m} / \mathrm{s}$. DLC-5 and DLC-7 showed a larger fluctuation in sliding velocity of $0.02 \mathrm{~m} / \mathrm{s}$ than that in sliding velocity of 0.1 $\mathrm{m} / \mathrm{s}$. Thus, DLC-6 had a shorter sliding life among the three of DLC coatings. Hydrogen-free DLC-8 deposited by cathode arc ion plating showed the highest friction coefficient $(0.10-0.50)$ and the largest fluctuation in sliding velocity of $0.02 \mathrm{~m} / \mathrm{s}$. In contrast, in the sliding velocity of $0.1 \mathrm{~m} / \mathrm{s}$, friction coefficient of DLC-8 was obviously decreasing, although it showed a higher range of value $(0.10-0.25)$ in the section $\mathrm{L}=0-2500 \mathrm{~m}$. It decreased to below 0.10 and became steady when the sliding distance exceed L $=2500 \mathrm{~m}$. DLC-8 showed a short lifetime because in $\mathrm{L}=5000$ - $7000 \mathrm{~m}$ the damage was occurred.

As above was remarked, DLC coatings showed a strong dependency on the sliding velocity. Figure 4 showed the average of friction coefficients in sliding velocity of $0.02 \mathrm{~m} / \mathrm{s}$ and $0.1 \mathrm{~m} / \mathrm{s}$. DLC coatings showed an obviously lower friction coefficient in sliding velocity of $0.1 \mathrm{~m} / \mathrm{s}$ than that of $0.02 \mathrm{~m} / \mathrm{s}$, although it was not seen with the DLC-6. DLC-1 and DLC-8 which had the higher friction coefficients in sliding velocity of $0.02 \mathrm{~m} / \mathrm{s}$ showed obviously decreasing friction coefficients in sliding velocity of $0.1 \mathrm{~m} / \mathrm{s}$. On the other hand, DLC-6 and DLC-7 which had the lower friction coefficients in sliding velocity of $0.02 \mathrm{~m} / \mathrm{s}$ did not show a clear decreasing in the higher velocity. It could be suggested that DLC-6 and DLC-7 had an excellent self-lubrication performance, and the effect of sliding velocity on the friction was not obvious under water lubrication. 


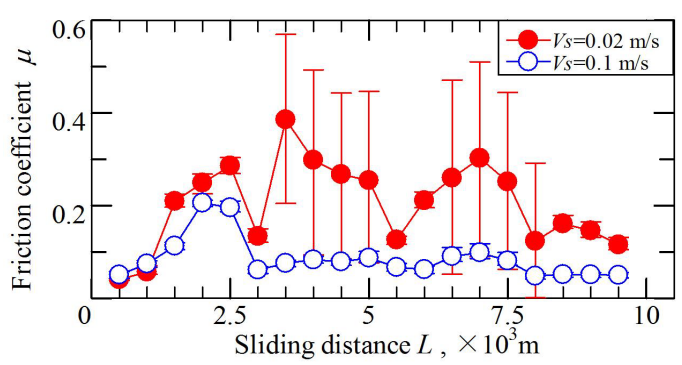

(a)

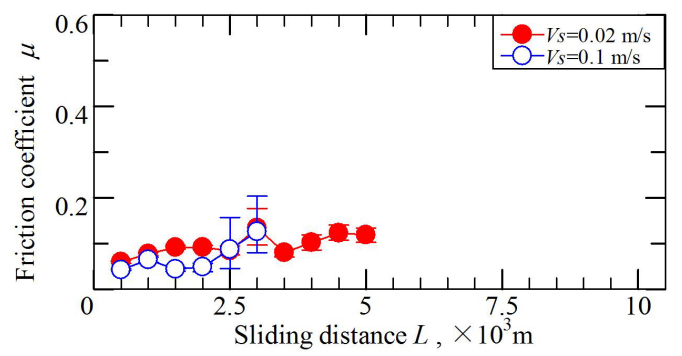

(c)

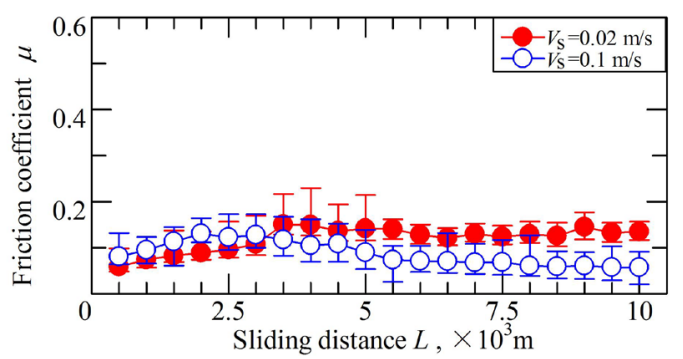

(e)

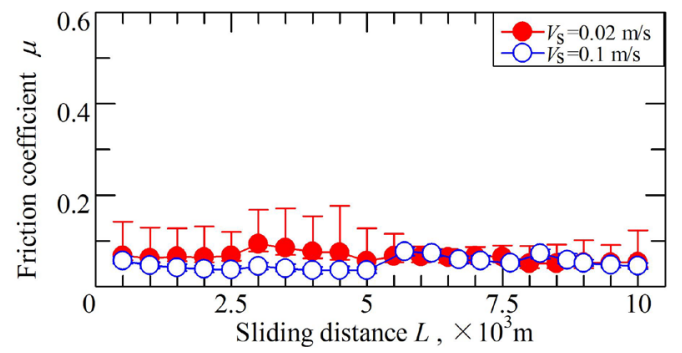

(g)

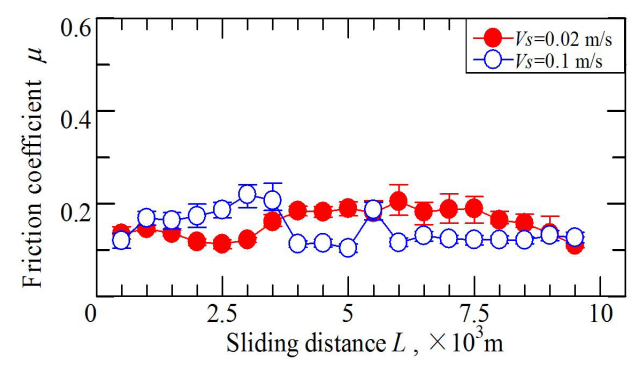

(b)

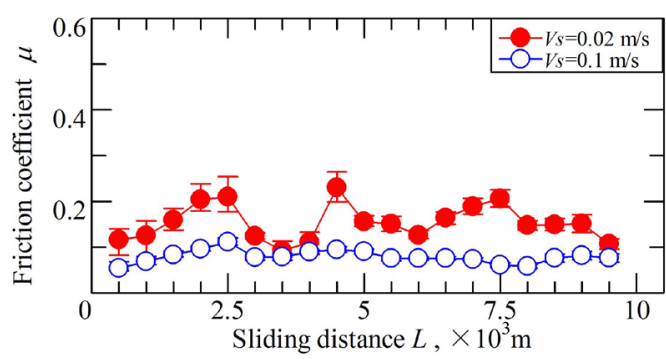

(d)

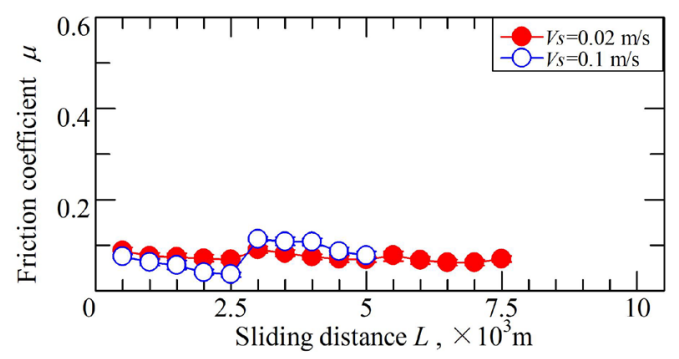

(f)

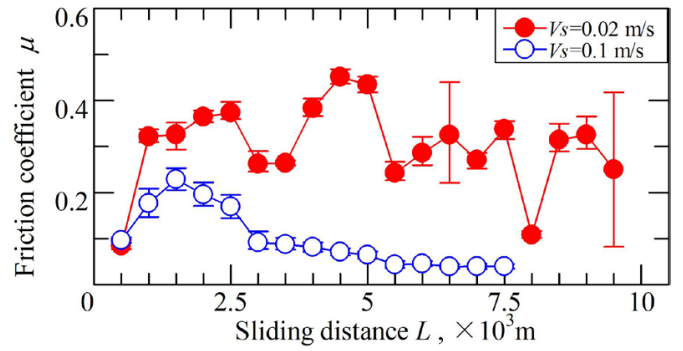

(h)

Figure 3. Relation between steady-state friction coefficient and sliding distance n. (a) DLC-1; (b) DLC-2; (c) DLC-3; (d) DLC-4; (e) DLC-5; (f) DLC-6; (g) DLC-7; (h) DLC-8.

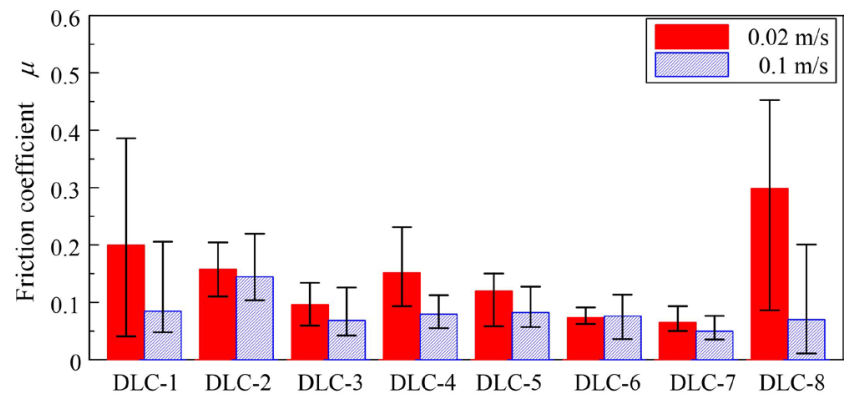

Figure 4. Friction coefficient in sliding velocity of $0.02 \mathrm{~m} / \mathrm{s}$ and $0.1 \mathrm{~m} / \mathrm{s}$. 


\subsection{Wear}

Figure 5 shows the specific wear rate of the DLC coatings with sliding velocities of $0.02 \mathrm{~m} / \mathrm{s}$ and $0.1 \mathrm{~m} / \mathrm{s}$ under water lubrication. DLC coatings showed a range of specific wear rates $0.5-6.0 \times 10^{-4} \mathrm{mg} / \mathrm{m}$, and it was clearly smaller than that of the substrate material SUS440C $\left(1.0 \times 10^{-2} \mathrm{mg} / \mathrm{m}\right)$. The wear rates of all DLC coatings tended to decrease with increasing sliding velocity, although this tendency was not obvious in DLC-6. DLC-1 and DLC-2 whose coatings were deposited with PVD showed a similar wear rate in sliding velocity of $0.02 \mathrm{~m} / \mathrm{s}$ and in sliding velocity of $0.1 \mathrm{~m} / \mathrm{s}$. In contrast, DLC-3 which deposited with the same PVD showed a larger wear rate of $6.0 \times 10^{-4} \mathrm{mg} / \mathrm{m}$ in sliding velocity of $0.02 \mathrm{~m} / \mathrm{s}$, and $4 \times 10^{-4} \mathrm{mg} / \mathrm{m}$ in sliding velocity of $0.1 \mathrm{~m} / \mathrm{s}$, respectively. DLC-4 deposited by multiple methods of PVD and CVD showed a wear rate of $3.5 \times 10^{-4} \mathrm{mg} / \mathrm{m}$ in sliding velocity of $0.02 \mathrm{~m} / \mathrm{s}$ and a small wear rate of $1.0 \times 10^{-4} \mathrm{mg} / \mathrm{m}$ in sliding velocity of $0.1 \mathrm{~m} / \mathrm{s}$. DLC-5, DLC- 6 and DLC-7 whose coatings were deposited with PVD showed obvious differences among the three DLC coatings. DLC-5 and DLC-7 showed larger specific wear rates approximately $6.0 \times 10^{-4} \mathrm{mg} / \mathrm{m}$, but showed lower specific wear rates approximately $2.0 \times 10^{-4} \mathrm{mg} / \mathrm{m}$. On the other hand, DLC-6 showed a lower and similar specific wear rate approximately $2.0 \times 10^{-4} \mathrm{mg} / \mathrm{m}$ both in sliding velocity of $0.02 \mathrm{~m} / \mathrm{s}$ and $0.1 \mathrm{~m} / \mathrm{s}$. Hydrogen-free DLC-8 showed a larger wear rate of $6.0 \times 10^{-4} \mathrm{mg} / \mathrm{m}$ in sliding velocity of $0.02 \mathrm{~m} / \mathrm{s}$. In contrast, the wear rate was $1.0 \times 10^{-4} \mathrm{mg} / \mathrm{m}$ in sliding velocity of $0.1 \mathrm{~m} / \mathrm{s}$, it was obviously decreased compared with in sliding velocity of $0.02 \mathrm{~m} / \mathrm{s}$.

All the DLC coatings showed the same tendency that wear rates decreased in increasing sliding velocity from $0.02 \mathrm{~m} / \mathrm{s}$ to $0.1 \mathrm{~m} / \mathrm{s}$, and the tendency was rather obviously except for DLC-6. From the result of the test it could be suggested that the higher sliding velocity the better wear behavior of DLC coatings under water lubrication. For the mechanism, the high applied velocity enhanced the graphitization process and therefore also influenced the friction behavior. The higher sliding velocity increased the contact frequency and the rate of temperature rise that facilitated the release hydrogen atoms from the $\mathrm{sp}^{3}$ structure [18] [19]. However, because of the difficulty in measuring the thickness of lubricant films and observing wear particles between friction surface of ring and disk specimens, investigating the cause of the increase in the number of surface asperities slid under a water friction condition with a decrease in sliding velocity is problematic. Further investigation is necessary to identify the reason for this.

Figure 6 showed the profile curve and the surface photos of each DLC coatings at the end of testing in sliding velocity of $0.02 \mathrm{~m} / \mathrm{s}$, the contact of disk wear part indicated in red. As shown in the micrographs, DLC-1, DLC-4 and DLC-8 showed a good wear resistant, they were not discovered damage and endurance were reached to $\mathrm{L}=10,000 \mathrm{~m}$ with a long lifetime, although DLC-8 had a deeper track was observed in the profile curve. The others coatings not showed a good wear resistant, because the damage and flaking were occurred. DLC-2 showed a little flaking was observed from the micrograph and profile curve when sliding distance $\mathrm{L}=7500$ 10,000 m. DLC-3 and DLC-5 were worn through, due to the high wear rate which is depicted in Figure 6(c) and Figure 6(e). Because the deep of damage was exceeded the film thickness, the films were completely removed. DLC-3 showed the shortest lifetime because the film endurance in the tests was L $=5000 \mathrm{~m}$. DLC-6 and DLC-7 showed an obviously damage were depicted in Figure 6(f) and Figure 6(g), that may be due to the flaking which were judged from the profile curve. The deep of damages were approximate equal to the film thickness, the films were gradually removed. DLC- 6 had a shorter lifetime because the film endurance in the tests was $\mathrm{L}=$ $7500 \mathrm{~m}$. In the sliding velocity of $0.1 \mathrm{~m} / \mathrm{s}$ showed the same tendency wear behavior of each DLC coatings.

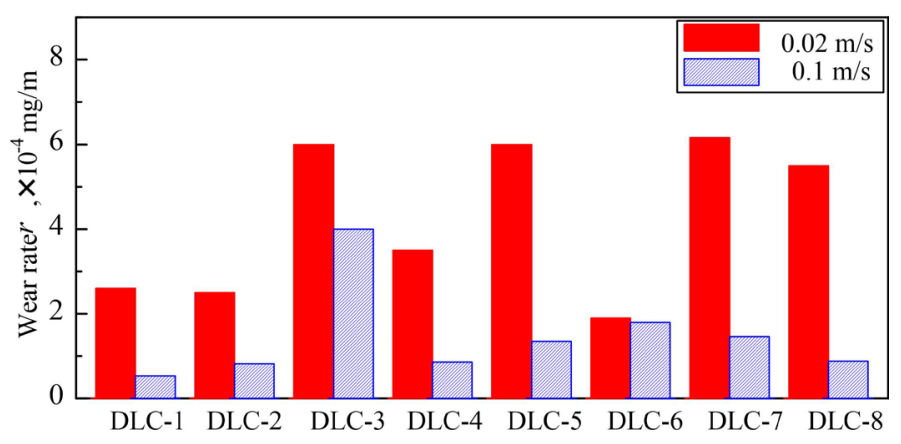

Figure 5. Specific wear rate. 


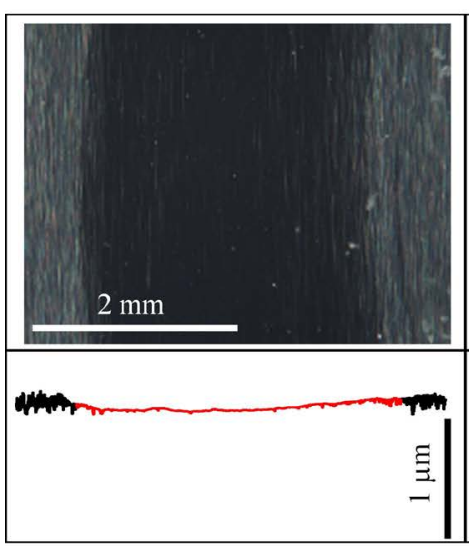

(a)

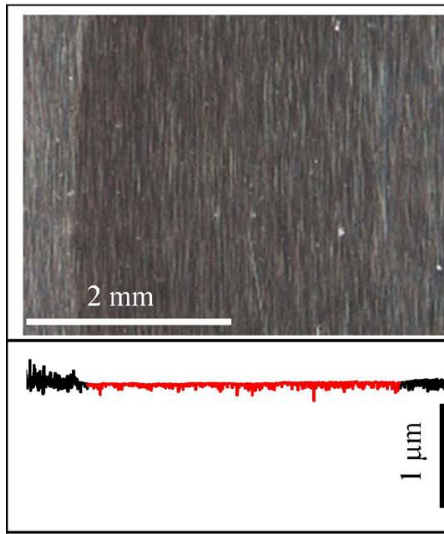

(d)

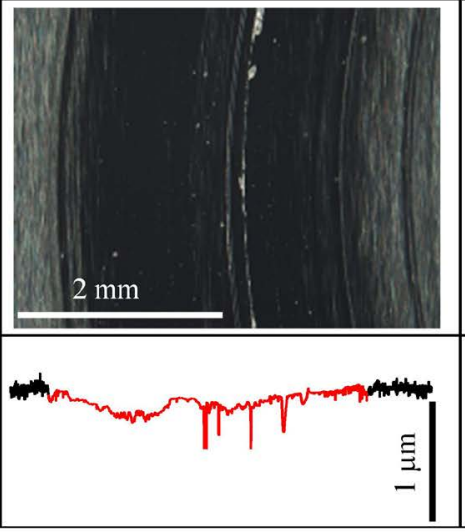

(b)

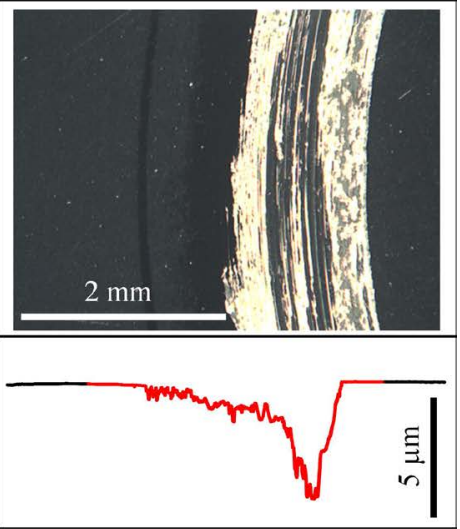

(c)

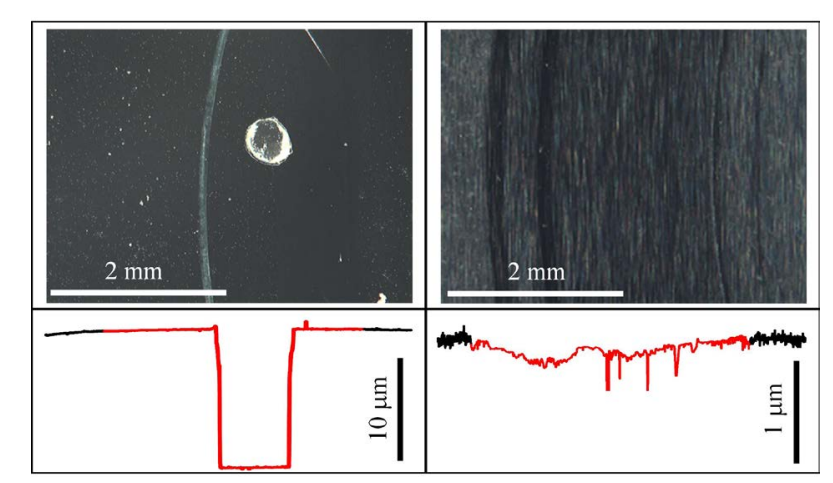

(g)

(h)

Figure 6. Profile curve and micrograph (Vs = $0.02 \mathrm{~m} / \mathrm{s}$ ). (a) DLC-1; (b) DLC-2; (c) DLC-3; (d) DLC-4; (e) DLC-5; (f) DLC-6; (g) DLC-7; (h) DLC-8.

\subsection{Wettability}

The importance of wetting is becoming increasingly obvious and its control is inevitable in many engineering applications, including tribology and interface nanotechnology [20] [21]. However, these parameters were typically neglected in tribological studies. Especially the water lubrication, due to the low viscosity of water, the water lubrication films thickness is very thin, the wettability are very important for DLC coatings under water lubrication. In this study, we investigated the effect ofwettability on friction coefficient and wear rate of DLC coatings under water lubrication. The parameter which characterizes the surfaces that we deemed essential is the surface wettability, measured by the contact angle $\theta$ [22] [23]. Figure 7 shows the contact angle of DLC coat- 


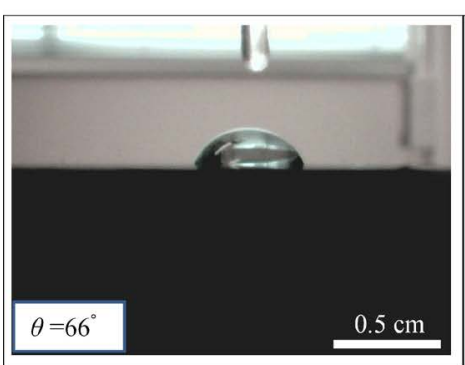

(a)

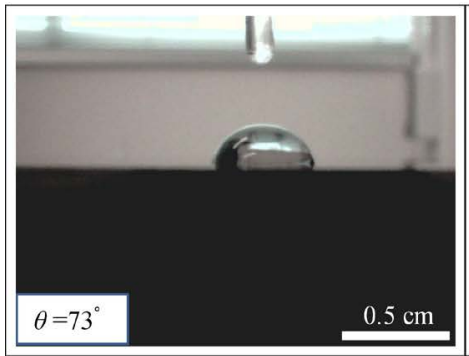

(d)

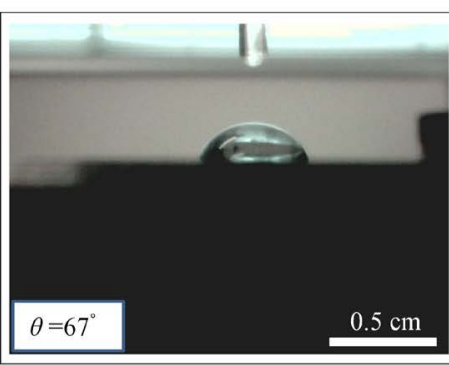

(b)

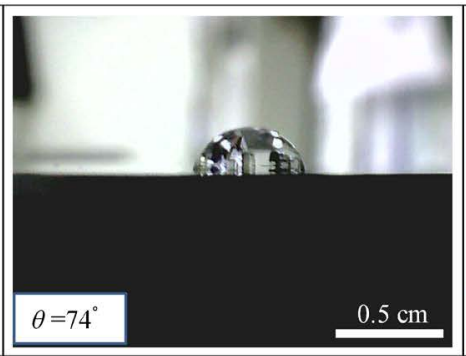

(e)



(c)

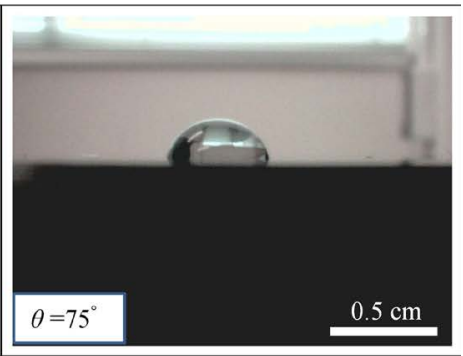

(f)

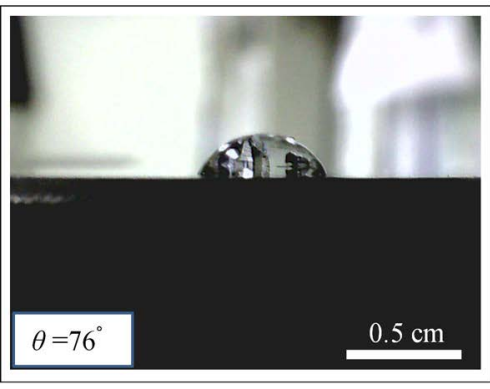

(g)

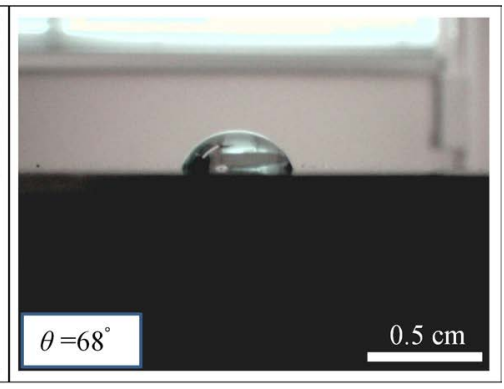

(h)

Figure 7. Surface contact angle. (a) DLC-1; (b) DLC-2; (c) DLC-3; (d) DLC-4; (e) DLC-5; (f) DLC-6; (g) DLC-7; (h) DLC-8.

ings. DLC coatings showed basically hydrophobic, because of the contact angle of the eight kinds of DLC films range was from $66^{\circ}$ to $75^{\circ}$. DLC-1 and DLC-2 whose coatings were deposited with PVD had a lower contact angle of $66^{\circ}$ and $67^{\circ}$, DLC-3 deposited with PVD had a contact angle of $70^{\circ}$. DLC-4 deposited by multiple PVD and CVD had a higher contact angle of $74^{\circ}$. DLC-5, DLC-6 and DLC-7 whose coatings were deposited with CVD had higher contact angle of $74^{\circ}, 75^{\circ}$ and $76^{\circ}$. Hydrogen-free DLC-8 had a low contact angle of $68^{\circ}$.

Figure 8 shows the relation between friction coefficient and contact angle in the sliding velocities of $0.02 \mathrm{~m} / \mathrm{s}$ and $0.1 \mathrm{~m} / \mathrm{s}$. In Figure 8(a) DLC-1, DLC-2, and DLC-3 whose coatings were deposited with PVD showed a tendency that with a higher contact angle of DLC coatings had a lower friction coefficient. DLC-4 with a high contact angle showed a lower friction coefficient. DLC-5, DLC-6 and DLC-7 which with higher contact angle showed obvious low friction coefficients, and it was showed a tendency that with a higher contact angle had a lower friction coefficient. DLC-8 with a lower contact angle showed the highest friction coefficient. Therefore, it seems reasonable to conclude that the friction coefficients were decreased with increasing contact angle in sliding velocity of $0.02 \mathrm{~m} / \mathrm{s}$. In contrast, DLC coatings showed a similar relation between friction coefficient and contact angle with the sliding velocity of $0.02 \mathrm{~m} / \mathrm{s}$, and they was showed a more obvious effect of the contact angle on the friction behavior in the velocity of $0.1 \mathrm{~m} / \mathrm{s}$, as shown in Figure 8(b).

From the result of Figure 8, it could be concluded that the higher contact angle showed the lower friction coefficient, and the tendency was obvious in the higher velocity. As the mechanism, it was a possibility that produce a lubricant layer of water between the molecules of water and the surfaces of the DLC coatings. It could be to build up a tribofilm that is able to carry the load and separate surfaces. When the contact angle of DLC 


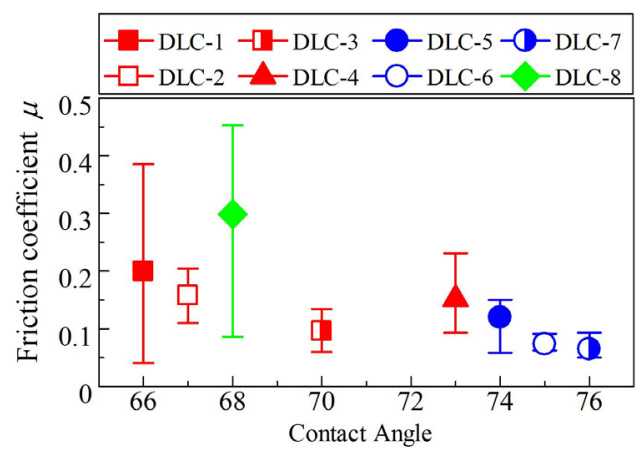

(a)

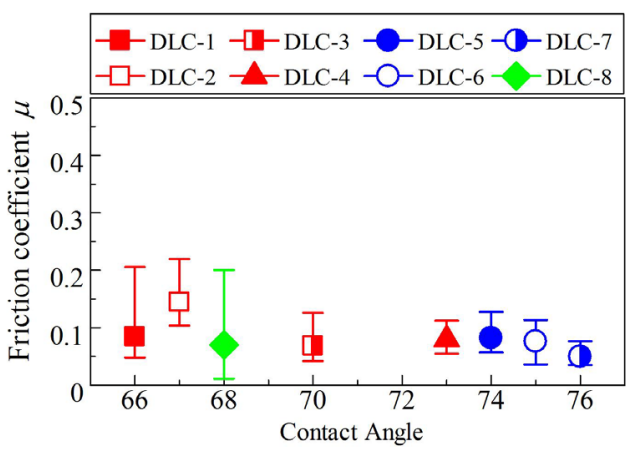

(b)

Figure 8. Relation between friction coefficient and contact angle. (a) $V \mathrm{~s}=0.02 \mathrm{~m} / \mathrm{s}$; (b) $V \mathrm{~s}=0.1 \mathrm{~m} / \mathrm{s}$.

coating was small, the layer of water which was initially on the disk has been quick taken away [22].

Figure 9 shows the relation between wear and contact angle in sliding velocity of $0.02 \mathrm{~m} / \mathrm{s}$ and $0.1 \mathrm{~m} / \mathrm{s}$. The results showed that the wettability was not an obviously effect on the wear of DLC coatings under water lubrication. DLC coatings were used the homogeneous coupling with the hydrophobic, because of with all these DLC coatings the values of the wear factor are very high in dry condition and with water lubrication [22]. In these DLC coatings the water lubrication is not very effective on the wear.

\subsection{Hardness}

Hardness is one of the most important parameters influencing the tribological behavior, and the hardness of the coating is basically determined by the deposition processes. The DLC coating hardness is presumed to be the main influential factor that dominates wear behavior [10]. However, in this paper, the different kinds of deposition methods were used for DLC coatings. The hardness of DLC coatings had been measured and the effect of the hardness of DLC coatings on friction and wear properties under water lubrication was investigated in this section. The hardness was measured using a nanoindenter. An average of 5 measurements was used to determine the hardness of the DLC coating in order to obtain a good statistical representation. In order to avoid surface and substrate effect, the depth of indentation was set at 100 - $200 \mathrm{~nm}$ which was lower $10 \%$ of the layer thickness [24]-[26]. Figure 10 shows the load-displacement curves of DLC coatings by nanoindenter. The mean values of hardness, modulus and the values of $\mathrm{H} / \mathrm{E}$ are summarized in Table 2. The hardness of the PVD-deposited DLC coatings DLC-1, DLC-2, and DLC-3 had a difference of 12.94, 32.11 and 28.87 GPa, respectively. DLC-5, DLC-6 and DLC-7 deposited by CVD had a small hardness of 21.35, 14.53 and 22.57 GPa. Hydrogen-free DLC-8 had the highest hardness of $53.63 \mathrm{GPa}$. Although DLC coatings showed the different of hardness and modulus, all of DLC coatings showed the similar values of H/E approximately 0.1 .

The effect of DLC hardness on friction behavior was shown in Figure 11. In Figure 11(a) DLC-1 with the lowest hardness showed a high friction coefficient, and with a high and similar hardness DLC-2 and DLC-3 showed a small and similar friction coefficient. Therefore, DLC-1, DLC-2, and DLC-3 whose coatings were deposited with PVD showed a reduction of friction with increasing hardness. DLC-5, DLC-6 and DLC-7 whose coatings were deposited with PVD also did not showed an obviously depend on hardness, although DLC-5 and DLC-7 showed a decreasing friction coefficient with increasing hardness. Hydrogen-free DLC-8 with the highest hardness showed the highest friction coefficient in sliding velocity of $0.02 \mathrm{~m} / \mathrm{s}$. In contrast, DLC coatings showed a small and similar friction coefficient in sliding velocity of $0.1 \mathrm{~m} / \mathrm{s}$, as shown in Figure 11(b). As shown in the results, the effect of hardness on friction coefficient was not obviously both at sliding velocity of $0.02 \mathrm{~m} / \mathrm{s}$ and $0.1 \mathrm{~m} / \mathrm{s}$, and it was more obvious in sliding velocity of $0.1 \mathrm{~m} / \mathrm{s}$.

Figure 12 shows the relation between hardness and wear rate of DLC coatings under water lubrication. As shown in Figure 12(a), the specific wear rate tended to increase with increases in the hardness of DLC coatings, although this tendency was not seen with DLC-2. DLC-1, DLC-4 and DLC-6 with a lower hardness showed a lower specific wear rate. DLC-5 and DLC-7 which deposited by CVD with a similar hardness showed a similar and high specific wear rate. Hydrogen-free DLC-8 with the highest hardness showed a high specific wear rate. DLC-2 with a higher hardness showed a lower specific wear rate. In contrast, in Figure 12(b), there is not a 


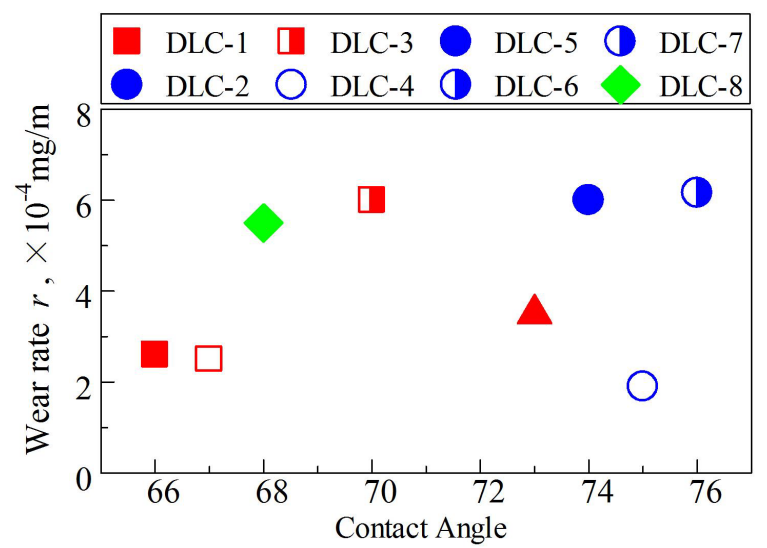

(a)

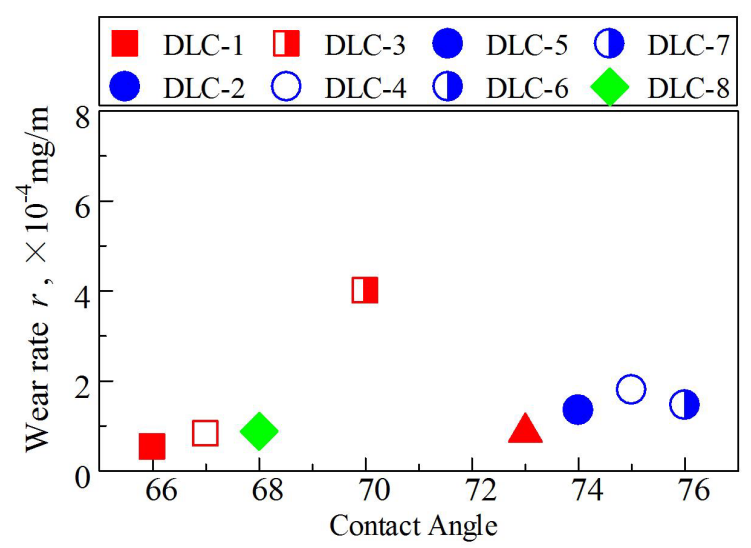

(b)

Figure 9. Relation between wear rate and contact angle. (a) Vs=0.02 m/s; (b) Vs $=0.1 \mathrm{~m} / \mathrm{s}$.

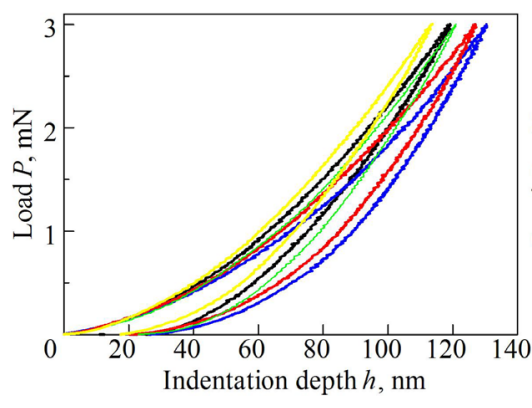

(a)

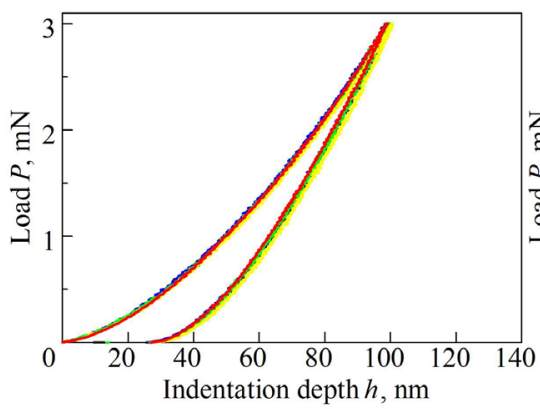

(d)

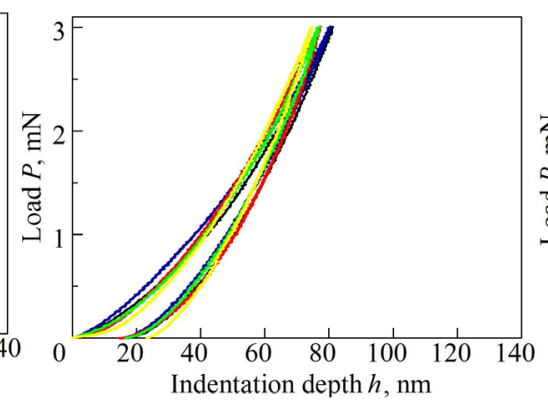

(b)

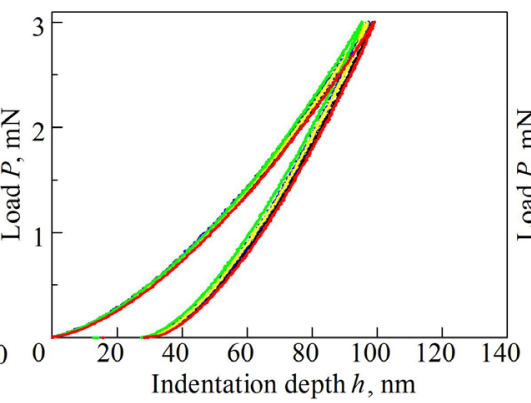

(e)

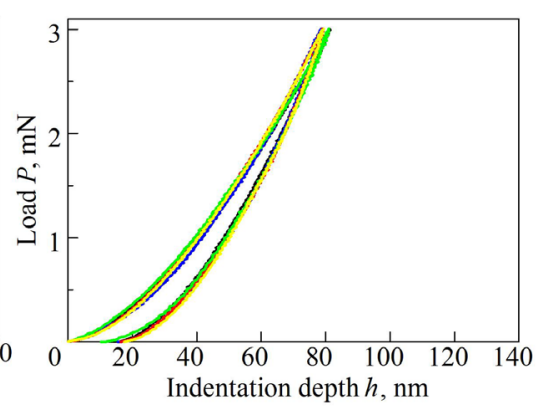

(c)

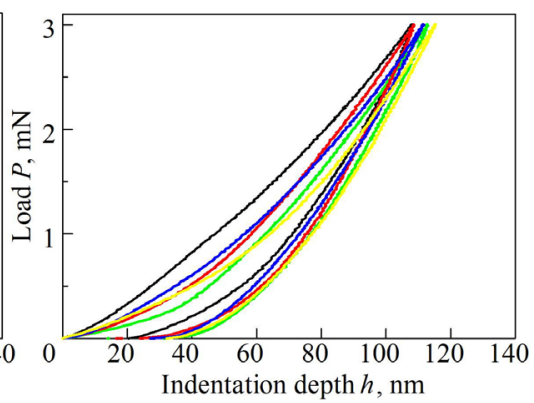

(f)

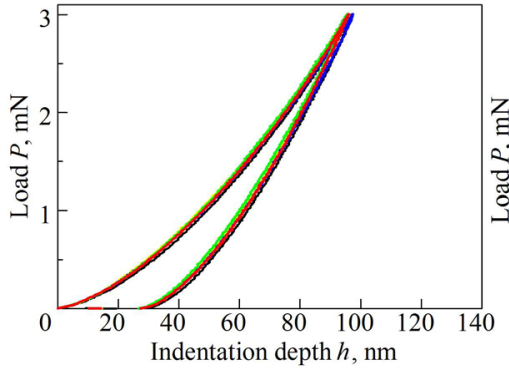

(g)

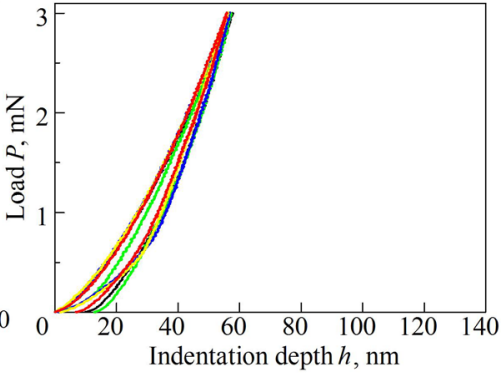

(h)

Figure 10. Load-displacement curves of DLC coatings. (a) DLC-1; (b) DLC-2; (c) DLC-3; (d) DLC-4; (e) DLC-5; (f) DLC-6; (g) DLC-7; (h) DLC-8. 


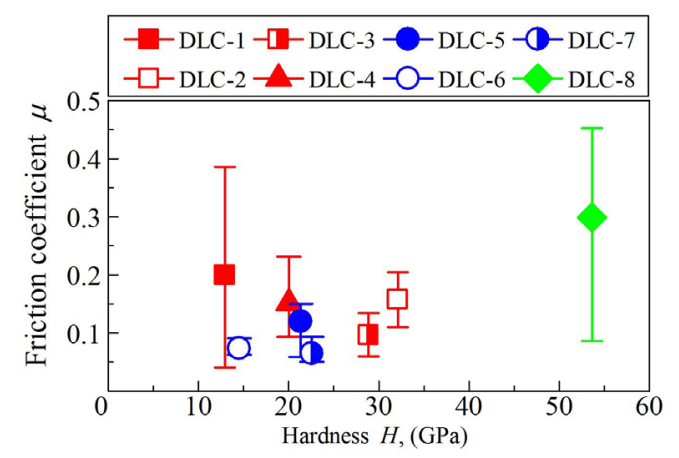

(a)

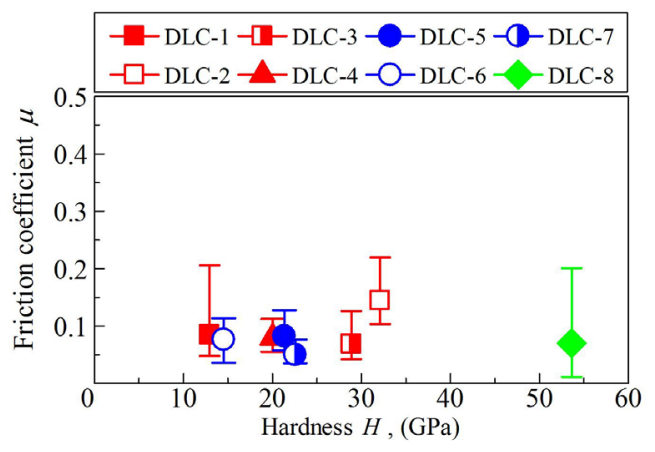

(b)

Figure 11. Relation between hardness and friction coefficient. (a) $V \mathrm{~s}=0.02 \mathrm{~m} / \mathrm{s}$; (b) $V \mathrm{~s}=0.1 \mathrm{~m} / \mathrm{s}$.

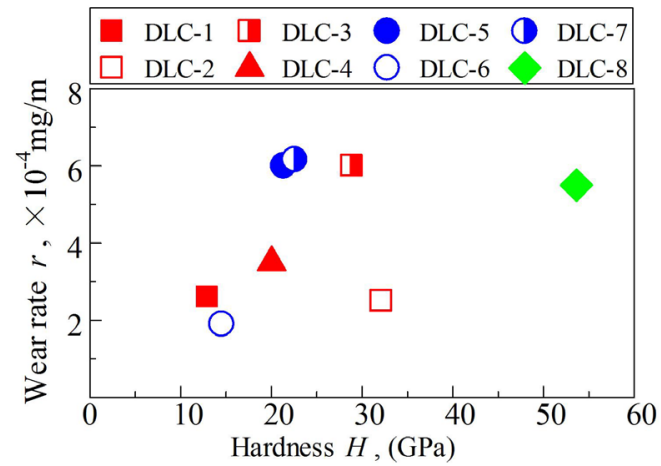

(a)

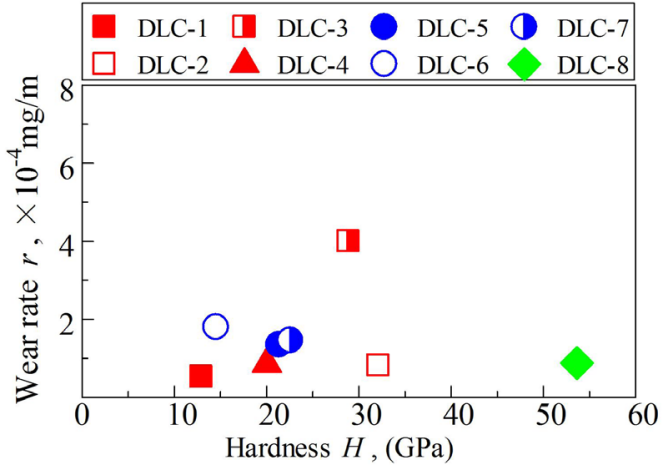

(b)

Figure 12. Relation between hardness and specific wear rates. (a) $V s=0.02 \mathrm{~m} / \mathrm{s}$; (b) $V \mathrm{~s}=0.1 \mathrm{~m} / \mathrm{s}$.

Table 2. Hardness H and elastic modulus E of DLC.

\begin{tabular}{cccc}
\hline Specimen & Hardness H $(\mathrm{GPa})$ & Elastic modulus E (GPa) & H/E \\
\hline DLC-1 & 12.94 & 107.57 & 0.12 \\
DLC-2 & 32.11 & 240.17 & 0.13 \\
DLC-3 & 28.87 & 223.82 & 0.13 \\
DLC-4 & 20.03 & 147.77 & 0.14 \\
DLC-5 & 21.35 & 156.84 & 0.13 \\
DLC-6 & 14.53 & 132.37 & 0.11 \\
DLC-7 & 22.57 & 156.82 & 0.14 \\
DLC-8 & 53.63 & 420.68 & 0.13 \\
\hline
\end{tabular}

clear relation between the specific wear rate and hardness in the eight kinds of DLC coatings under the sliding velocity of $0.1 \mathrm{~m} / \mathrm{s}$. DLC coatings which with the differences of hardness showed a similar and low specific wear rate except for DLC-6. DLC-6 showed the highest specific wear rate than others. As the results, the specific wear rate increased with increasing the hardness of DLC coatings under the sliding velocity of $0.02 \mathrm{~m} / \mathrm{s}$. In contrast, the tendency was not obvious in the higher sliding velocity of $0.1 \mathrm{~m} / \mathrm{s}$ under water lubrication.

\subsection{Adhesion}

The adhesion of films is one of the most important and difficult tasks of surface engineering. It is known that numerous parameters have an influence on coating adhesion including stress in the film, contamination and 
chemical bonding between the film and the substrate, and the physical properties and roughness of the substrate. The major disadvantage of deposition of DLC coating technical applications is often caused by very high internal compressive stress in these coatings [27] [28]. Thus under water lubrication, due to the low viscosity of water, the water lubrication films thickness is very thin, the tribological performance of DLC coatings maybe proceed in boundary lubrication [29]. It was a very important factor to affect the tribological performance of DLC coatings under water lubrication.

In order to improve the adhesion of DLC coatings, DLC-1 and DLC-2 whose coatings were deposited with PVD were deposited with a CrN interlayer. DLC-2 and DLC-4 were doped with some tungsten and some silicon, respectively. DLC-6 and DLC-7 were deposited with a thick film thickness. As the result shown in Figure 6, DLC-1 and DLC-2 with a CrN interlayer showed a long sliding lifetime L $=10,000 \mathrm{~m}$, and DLC-2 a little flaking was occurred at sliding distance $\mathrm{L}=10,000 \mathrm{~m}$. In contrast, DLC-3 deposited with PVD showed the shortest sliding lifetime $\mathrm{L}=5000 \mathrm{~m}$. DLC-4 had a long sliding lifetime $\mathrm{L}=10,000 \mathrm{~m}$. Hydrogen-free DLC-8 had a long sliding lifetime $\mathrm{L}=10,000 \mathrm{~m}$, although it had a mass specific wear rate. DLC-6 and DLC-7 with the thicker film thickness flaking were occurred at when the sliding distance $\mathrm{L}=7500 \mathrm{~m}$ for DLC- 6 and sliding distance $\mathrm{L}=$ $10,000 \mathrm{~m}$ for DLC-7.

The damaged portion of the flaking were analysed with SEM about the two kinds of DLC coatings which deposited with a CrN interlayer DLC-2 and another without interlayer DLC-6. Figure 13 showed the SEM photograph and XRD line analysis of DLC-2 and DLC-6, respectively. In Figure 13(a), DLC-2 showed a greater detection intensity of $\mathrm{W}$ and $\mathrm{C}$ on the non-damaged portion, and a smaller detected intensity of Fe on the flaking damaged portion. It could be suggested that the flaking was occurred from intermediate layer, not yet reach to the substrate. In Figure 13(b), DLC-6 showed a greater Fe and Cr detected intensity on the flaking damaged portion, and a greater $\mathrm{C}$ detected intensity on the non-damaged portion, the flaking was occurred from the interface of the DLC film and substrate was considered.

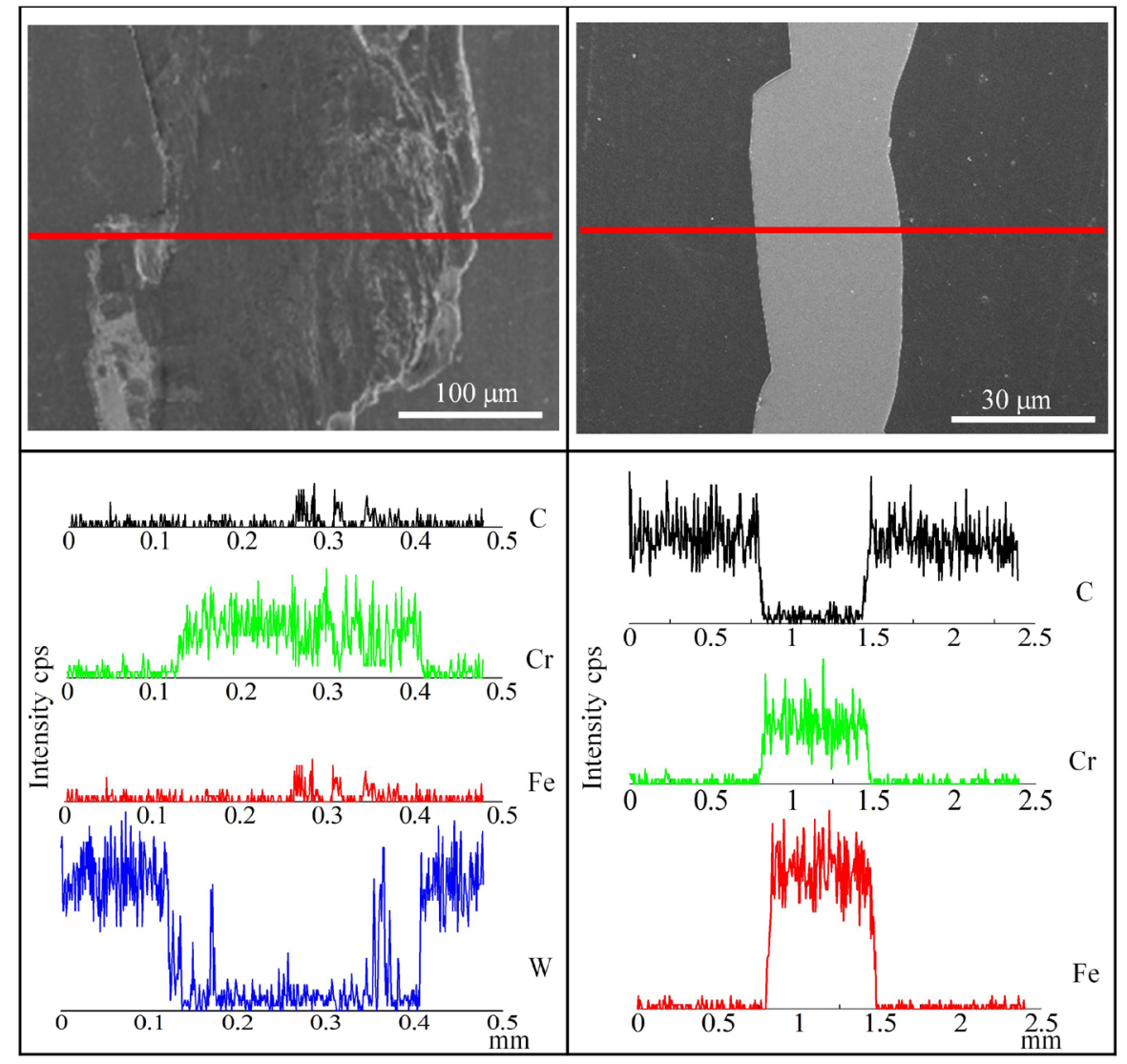

(a)

(b)

Figure 13. SEM photograph and XRD line analysis. (a) DLC-2; (b) DLC-6. 
From what had been discussed above, we could concluded that deposited with a CrN interlayer and doped with some silicon of DLC coatings showed excellent adhesion properties. Although Hydrogen-free DLC had good adhesion property, it showed a higher friction coefficient and wear rate than others. On the other hand, DLC deposited by CVD showed an excellent tribological characteristic, although had a short lifetime. A continuous examination of DLC coatings would strengthen the adhesion under water lubrication.

\section{Conclusions}

In this study, eight kinds of DLC coatings were evaluated by water-lubricated tribological tests. The main conclusions that can be drawn from the results are the following:

1) DLC coatings showed low friction coefficient and excellent wear resistance under water lubrication. The tribological properties of DLC coatings were strongly affected by the deposition methods. DLC coatings which deposited by PVD and cathode arc ion plating had comparatively high and un-steady friction coefficients. DLC coatings which deposited by CVD had comparatively low and steady friction coefficients. DLC coatings which deposited by PVD and cathode arc ion plating had better wear resistant than those deposited by CVD. Moreover, all DLC coatings showed better tribological properties in the higher sliding velocity.

2) DLC coatings showed a basically hydrophobic characteristic of wettability. DLC coatings which deposited by CVD had a rather high contact angle, while DLC coatings deposited by PVD and cathode arc ion plating had a rather low contact angle. The tendency showed that friction coefficient decreased in increasing contact angle, and it was obvious in the higher velocity.

3) DLC coatings showed a large range of surface hardness. Hydrogen-free DLC coatings deposited by cathodearc ion plating had the highest hardness. DLC coatings which deposited by CVD had a lower hardness thanthose deposited by PVD and cathode arc ion plating. Furthermore, the friction coefficient of DLC coatings deposited by cathode arc ion plating was higher than those deposited by PVD and CVD. The specific wear rates tended to increase with increases in the hardness of DLC coatings.

\section{Acknowledgements}

This research was partially supported in the Science Student Encourage Research Funding, Graduate School of Science and Technology, Okayama University and Grants in aid for Scientific Research. The author would like to express gratitude to graduate student of Master's Course in Okayama University.

\section{References}

[1] Tokoro, M., Aiyama, Y., Masuko, M., Suzuki, A., Ito, H. and Yamamoto, K. (2009) Improvement of Tribological Characteristics under Water Lubrication of DLC-Coatings by Surface Polishing. Wear, 267, 2167-2172. http://dx.doi.org/10.1016/j.wear.2009.04.009

[2] Lancaster, J.K. (1990) A Review of the Influence of Environment Humidity and Water of Friction Lubrication and Wear. Tribology International, 23, 371-389. http://dx.doi.org/10.1016/0301-679X(90)90053-R

[3] Bartz, W.J. (1998) Lubricants and the Environment. 31, 35-47.

[4] Masuko, M., Suzuki, A., Sagae, Y., Tokoro, M. and Yamamoto, K. (2006) Friction Characteristics of Inorganic or Organic Thin Coatings on Solid Surfaces under Water Lubrication. Tribology International, 39, 1601-1608.

[5] Robertson, J. (2002) Diamond-Like Amorphous Carbon. Materials Science and Engineering, 37, $129-281$. http://dx.doi.org/10.1016/S0927-796X(02)00005-0

[6] Hirvonen, J.-P., Koskinen, J., Jervis, J.R. and Nastasi, M. (1996) Present Progress in the Development of Low Friction Coatings. Surface and Coatings Technology, 80, 139-150. http://dx.doi.org/10.1016/0257-8972(95)02701-7

[7] Grill, A. (1997) Tribology of Diamond Like Carbon and Related Materials: An Updated Review. Surface and Coatings Technology, 94/95, 507-513. http://dx.doi.org/10.1016/S0257-8972(97)00458-1

[8] Donnct, C. (1998) Recent Progress on the Tribology of Doped Diamond-Like and Carbon Alloy Coatings: A Review. Surface and Coatings Technology, 100/101, 180-186. http://dx.doi.org/10.1016/S0257-8972(97)00611-7

[9] Sharma, N., Kumar, N., Dash, S., Das, C.R., Subba Rao, R.V., Tyagi, A.K. and Raj, B. (2012) Scratch Resistance and Tribological Properties of DLC Coatings under Dry and Lubrication Conditions. Tribology International, 56, 129-140. http://dx.doi.org/10.1016/j.triboint.2012.06.020

[10] Yamamoto, K. and Matsukado, K. (2006) Effect of Hydrogenated DLC Coating Hardness on the Tribological Properties under Water Lubrication. Tribology International, 39, 1609-1614. http://dx.doi.org/10.1016/j.triboint.2006.01.004 
[11] Ronkainen, H., Varjus, S. and Holmberg, K. (2001) Tribological Performance of Different DLC Coatings in Water-Lubricated Conditions. Wear, 249, 267-271. http://dx.doi.org/10.1016/S0043-1648(01)00561-0

[12] Ronkainen, H., Varjus, S. and Holmberg, K. (1998) Friction and Wear Properties in Dry, Water- and Oil-Lubricated DLC against Alumina and DLC against Steel Contacts. Wear, 222, 120-128. http://dx.doi.org/10.1016/S0043-1648(98)00314-7

[13] Statuti, R.P.C.C., Radi, P.A., Santos, L.V. and Trava-Airold, V.J. (2009) A Tribological Study of the Hybrid Lubrication of DLC Films with Oil and Water. Wear, 267, 1208-1213. http://dx.doi.org/10.1016/j.wear.2008.11.033

[14] Persson, K. and Gåhlin, R. (2003) Tribological Performance of a DLC Coating in Combination with Water-Based Lubricants. Tribology International, 36, 851-855. http://dx.doi.org/10.1016/S0301-679X(03)00103-8

[15] Erdemir, A. (2001) The Role of Hydrogen in Tribological Properties of Diamond-Like Carbon Films. Surface and Coatings Technology, 146-147, 292-297. http://dx.doi.org/10.1016/s0257-8972(01)01417-7

[16] Kalin, M. and Vižintin, J. (2006) Differences in the Tribological Mechanisms When Using Non-Doped, Metal-Doped (Ti, WC), and Non-Metal-Doped (Si) Diamond-Like Carbon against Steel under Boundary Lubrication, with and without Oil Additives. Thin Solid Films, 515, 2734-2747. http://dx.doi.org/10.1016/j.tsf.2006.03.034

[17] Uchidate, M., Liu, H., Iwabuchi, A. and Yamamoto, K. (2007) Effects of Water Environment on Tribological Properties of DLC Rubbed against Stainless Steel. Wear, 263, 1335-1340. http://dx.doi.org/10.1016/j.wear.2006.10.024

[18] Kim, D.-W. and Kim, K.-W. (2014) Effects of Sliding Velocity and Ambient Temperature on the Friction and Wear of a Boundary-Lubricated, Multi-Layered DLC Coating. Wear, 315, 95-102.

[19] Ronkainen, H., Varjus, S., Koskinen, J. and Holmberg, K. (2001) Differentiating the Tribological Performance of Hydrogenated and Hydrogen-Free DLC Coatings. Wear, 249, 260-266. http://dx.doi.org/10.1016/S0043-1648(01)00558-0

[20] Kalin, M. and Polajnar, M. (2014) The Wetting of Steel, DLC Coatings, Ceramics and Polymers with Oils and Water: The Importance and Correlations of Surface Energy, Surface Tension, Contact Angle and Spreading. Applied Surface Science, 293, 97-108. http://dx.doi.org/10.1016/j.apsusc.2013.12.109

[21] Kalin, M. and Polajnar, M. (2013) The Correlation between the Surface Energy, the Contact Angle and the Spreading Parameter, and Their Relevance for the Wetting Behaviour of DLC with Lubricating Oils. Tribology International, 66, 225-233. http://dx.doi.org/10.1016/j.triboint.2013.05.007

[22] Borruto, A., Crivellone, G. and Marani, F. (1998) Influence of Surface Wettability on Friction and Wear Tests. Wear, 222, 57-65.

[23] Pawlak, Z., Urbaniak, W. and Oloyede, A. (2011) The Relationship between Friction and Wettability in Aqueous Environment. Wear, 271, 1745-1749. http://dx.doi.org/10.1016/j.wear.2010.12.084

[24] Fischer-Cripps, A.C., Karvánková, P. and Vepřek, S. (2006) On the Measurement of Hardness of Super-Hard Coatings. Surface and Coatings Technology, 200, 5645-5654.

[25] Golovin, Y.I. (2008) Nanoindentation and Mechanical Properties of Solids in Submicrovolumes, Thin Near-Surface Layers, and Films: A Review. Physics of the Solid State, 50, 2205-2236. http://dx.doi.org/10.1134/S1063783408120019

[26] Mabuchi, Y., Higuchi, T., Inagaki, Y., Kousaka, H. and Umehara, N. (2013) Wear Analysis of Hydrogen-Free Diamond-Like Carbon Coatings under a Lubricated Condition. Wear, 298-299, 48-56. http://dx.doi.org/10.1016/j.wear.2012.11.046

[27] Bonetti, L.F., Capote, G., Santos, L.V., Corat, E.J. and Trava-Airoldi, V.J. (2006) Adhesion Studies of Diamond-Like Carbon Films Deposited on Ti6Al4V Substrate with a Silicon Interlayer. Thin Solid Films, 515, 375-379. http://dx.doi.org/10.1016/j.tsf.2005.12.154

[28] Koski, K., Hölsä, J., Ernoult, J. and Rouzaud, A. (1996) The Connection between Sputter Cleaning and Adhesion of Thin Solid Films. Surface and Coatings Technology, 80, 195-199. http://dx.doi.org/10.1016/0257-8972(95)02710-6

[29] Kleinsorge, B., Ilie, A., Chhowalla, M., Fukarek, W., Milne, W.I. and Robertson, J. (1998) Electrical and Optical Properties of Boronated Tetrahedrally Bonded Amorphous Carbon (ta-C:B). Diamond and Related Materials, 7, 472476. http://dx.doi.org/10.1016/S0925-9635(97)00238-0 